\title{
Protections for clinical trials in low and middle income countries need strengthening not weakening
}

In this Analysis article by Rafael Dal-Ré and colleagues (BMJ 2014;349:g4254, doi:10.1136/bmj.g4254), we failed to take in two corrections at the proof stage. In the second paragraph of the section on likelihood of benefit, the fifth sentence should have read: "Thirty per cent of all new medicines starting phase III fail to conclude it successfully. .." In table 2, the second row should be labelled "Cycle times" not "Average cycle time." Lastly, the authors would also like to point out that the median number of participants in the table refers to all three trial phases.

Cite this as: BMJ 2014;349:94516

๑) BMJ Publishing Group Ltd 2014 